\title{
Thromboxane Production
}

National Cancer Institute

\section{Source}

National Cancer Institute. Thromboxane Production. NCI Thesaurus. Code C40655.

Thromboxane Production consists of synthesis of widely distributed compounds formed by cyclooxygenase from polyunsaturated fatty acid prostaglandin endoperoxides (thromboxanes) and have a regulatory effect on platelet aggregation, contraction of arteries, and other biological effects. 